\title{
Comparison of the laryngeal view during intubation using Airtraq and Macintosh laryngoscopes in patients with cervical spine immobilization and mouth opening limitation
}

\author{
Jae-Chul Koh, Jong Seok Lee, Youn-Woo Lee, and Chul Ho Chang \\ Department of Anesthesiology and Pain Medicine and Anesthesia and Pain Research Institute, Yonsei University College of Medicine, \\ Seoul, Korea
}

Background: For patients suspicious of cervical spine injury, a Philadelphia cervical collar is usually applied. Application of Philadelphia cervical collar may cause difficult airway. The aim of this study was to evaluate the laryngeal view and the success rate at first intubation attempt of the Airtraq and conventional laryngoscopy in patients with simulated cervical spine injury after application of a Philadelphia cervical collar.

Methods: Anesthesia was induced with propofol, remifentanil, and rocuronium. After a Philadelphia cervical collar applied, patients were randomly assigned to tracheal intubation with an Airtraq (Group A, n = 25) or with conventional laryngoscopy (Group L, $\mathrm{n}=25$ ). Measurements included intubation time, success rate of first intubation attempt, number of intubation attempts, and percentage of glottic opening (POGO) score. Mean blood pressure and heart rate were also recorded at baseline, just before and after intubation.

Results: The success rate of the first attempt in Group A (96\%) was significantly greater than with the Group L (40\%). POGO score was significantly greater in Group A ( $84 \pm 20 \%)$ than in Group L $(6 \pm 11 \%)$. The duration of successful intubation at first tracheal intubation attempt and hemodynamic changes were not significantly different between the two groups.

Conclusions: The Airtraq offers a better laryngeal view and higher success rate at first intubation attempt in patients who are applied with a Philadelphia cervical collar due to suspicion of cervical spine injury. (Korean J Anesthesiol 2010; 59: 314-318)

Key Words: Airtraq, Immobilization, Intubation, Laryngoscopes.

Received: April 30, 2010. Revised: 1st, May 22, 2010; 2nd, June 16, 2010. Accepted: June 29, 2010.

Corresponding author: Chul Ho Chang, M.D., Department of Anesthesiology and Pain Medicine, Yonsei University College of Medicine, Dogokdong, Gangnam-gu, Seoul 135-270, Korea. Tel: 82-2-2019-3528, Fax: 82-2-3463-0940, E-mail: anezzang@yuhs.ac

(c) This is an open-access article distributed under the terms of the Creative Commons Attribution Non-Commercial License (http:// creativecommons.org/licenses/by-nc/3.0/), which permits unrestricted non-commercial use, distribution, and reproduction in any medium, provided the original work is properly cited. 


\section{Introduction}

Failure to adequately immobilize the neck during tracheal intubation in patients with cervical spine injuries can result in a devastating neurological outcome [1]. Therefore, laryngoscopists often encounter patients with a Philadelphia neck collar (Tracheostomy Philadelphia Collar, Philadelphia Cervical Collar Co., Thorofare, NJ, USA) because many clinics employ this device to immobilize the patient's cervical spine when cervical spine injury is suspected.

However, with cervical spine immobilization, it becomes more difficult to visualize the larynx by conventional laryngoscopy [2-7]. An alternative laryngoscopy device that incorporates video or fiberoptic imaging into the blade or stylet appears to improve the glottic view, facilitating rapid intubation and better outcomes [3-6].

The Airtraq (AirTraq ${ }^{\circledR}$, Prodol Meditec, Vizcaya, Spain) is a novel intubation device that has been developed to aid laryngoscopy (Fig. 1) [5]. The device provides a high quality indirect view of the glottis, removing the requirement to align the oral, pharyngeal and tracheal axes.

This study hypothesized that the Airtraq may overcome mouth opening limitation and poor laryngeal view of conventional laryngoscopy when Philadelphia neck collar is applied $[8,9]$. This study evaluated the use of this new device by experienced anesthesiologists in patients with neck immobilization due to wear of a Philadelphia cervical collar.

\section{Materials and Methods}

After obtaining approval by the Institutional Review Board and written informed consent from the patients, this study investigated 50 patients, aged 20 to 60 years, with American Society of Anesthesiologists physical status I-II who were

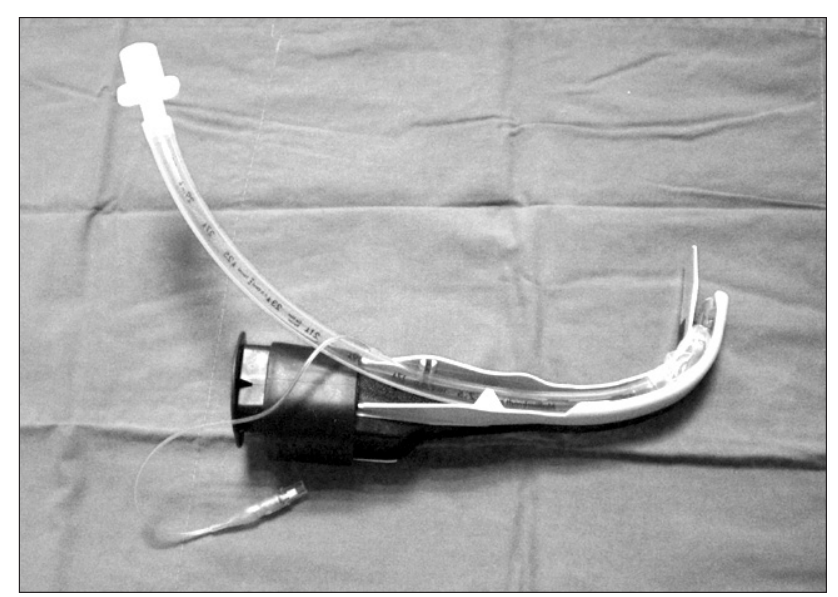

Fig. 1. Photograph of the AirTraq. scheduled to undergo surgical procedures necessitating tracheal intubation (Table 1).

The exclusion criteria were the risk factors for increased dental injury, pulmonary aspiration, functional or anatomical deformities in the airway (i.e., asthma, burn, and tumor), anticipated airway difficulties (i.e., Mallampatti grade IV or having prior history of difficult airway), and body mass index greater than 30. Patients were also excluded if surgery required one lung ventilation or a different endotracheal tube other than the conventional endotracheal tube used.

Glycopyrrolate $0.1 \mathrm{mg}$ and midazolam $0.03-0.05 \mathrm{mg} / \mathrm{kg}$ were administered intravenously 30 minutes before the induction of anesthesia as premedication. The Mallampatti classification and thyromental distance were measured and recorded before the patients were anesthetized. The patients were monitored using an electrocardiograph, pulse oximeter, and noninvasive blood pressure monitor. After monitoring, baseline blood pressure and heart rate were recorded.

General anesthesia was induced by intravenous propofol 1.5 $\mathrm{mg} / \mathrm{kg}$ and remifentanil $0.5 \mu \mathrm{g} / \mathrm{kg}$ followed by a continuous infusion of $0.1 \mu \mathrm{g} / \mathrm{kg} / \mathrm{min}$. After the induction of anesthesia, all patients were manually ventilated with sevoflurane $2.5 \%$ in $100 \%$ oxygen, and rocuronium $0.8 \mathrm{mg} / \mathrm{kg}$ was administered after confirming suppression of eyelash reflex.

After administering rocuronium, the pillow was removed and an appropriately sized rigid Philadelphia cervical collar was positioned around the neck. The patients were then allocated randomly to tracheal intubation with an Airtraq (Group A) or Macintosh laryngoscope (Group L). The randomization was based on computer-generated codes that were maintained in sequentially numbered opaque envelopes. After rocuronium administration, muscle relaxation was confirmed by the loss of the TOF twitch, and tracheal intubation was then performed using one of the study devices.

For patients allocated to Group A, an Airtraq with a preloaded curved tracheal tube $(7 \mathrm{~mm}$ internal diameter for women and 8

Table 1. Patients' Characteristics

\begin{tabular}{lcc}
\hline & $\begin{array}{c}\text { Group L } \\
(\mathrm{n}=25)\end{array}$ & $\begin{array}{c}\text { Group A } \\
(\mathrm{n}=25)\end{array}$ \\
\hline Age (yr) & $44.0 \pm 9.4$ & $45.5 \pm 7.9$ \\
Sex (M/F) & $9 / 16$ & $9 / 16$ \\
Weight (kg) & $61.8 \pm 10.6$ & $64.9 \pm 9.3$ \\
Height (cm) & $160.9 \pm 8.6$ & $165.2 \pm 7.8$ \\
ASA class (I/II) & $18 / 7$ & $22 / 3$ \\
Thyromental distance (cm) & $6.3 \pm 0.7$ & $5.9 \pm 0.5$ \\
Malampatti classification (I/II/III) & $6 / 15 / 4$ & $4 / 16 / 5$ \\
\hline
\end{tabular}

Values are number or mean \pm SD. There were no significant differences between the two groups. Group L: conventional laryngoscope group, Group A: Airtraq group. ASA class: American Society of Anesthesiologist Classification. 
$\mathrm{mm}$ for men) was inserted into the mouth and the Airtraq was positioned at the glottis so that the glottis could be observed at the center of the scope's monitor. The tracheal tube was then advanced into the trachea, and the Airtraq was detached and removed from the mouth. Finally, the respiratory circuit was connected and ventilation was confirmed by capnography.

For the patients assigned to Group L, the best possible view of the glottis was obtained in females and males using a no. 3 and no. 4 Macintosh laryngoscope, respectively. Tracheal tubes with a 7 and $8 \mathrm{~mm}$ internal diameter for women and men, respectively, were used.

Tracheal intubation was performed by one experienced anesthesiologist who had experienced more than 30 intubations with the Airtraq. During the procedures, an unblinded observer recorded the intubation time, heart rate and mean blood pressure at baseline, just before and after intubation. A photograph was taken by an observer when the best possible view of the glottis was obtained.

In each group, a tracheal intubation attempt was considered to have failed if it could not be accomplished within 90 seconds. When the first intubation attempt failed, the intubation attempt was terminated and a second attempt was made after mask ventilation of 1 minute. The second attempt was made by rotating the Airtraq and applying cricoid pressure in Group A and applying a cricoid pressure and stylets in Group $\mathrm{L}$ within 90 seconds. In the event of failed second intubation attempt, the Philadelphia collar was removed and the patients were intubated under direct vision using a conventional laryngoscope with a pillow.

The observer recorded the total number of intubation attempts and the intubation time, which was defined as the time from picking up the device until the first appearance of the capnograph wave form. Any events that occurred during intubation, such as lip or dental injury, were also recorded.

After obtaining a photograph of the best glottic view for each

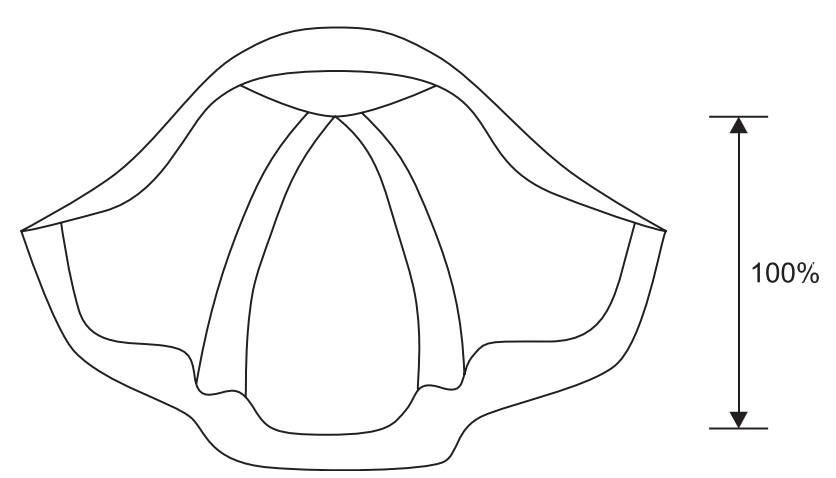

Fig. 2. The percentage of glottic opening score ranges from $0 \%$ when none of glottis can be seen to $100 \%$ when the entire glottis can be seen. device, 2 blinded anesthesiologists were asked to report the vocal cord visualization using the percentage of glottic opening (POGO) score (Fig. 2) [10], and the mean values were used for analysis. Based on the assumption of $\alpha=0.05,1-\beta=0.8$, $\mathrm{SD}=12$ and difference of the POGO score $=10$ which were estimated from a pilot study, the minimum number of samples was 24 . The patients' demographics were compared using chisquare test and t-test. The POGO score, insertion time, insertion attempt were compared using t-test. The hemodynamic data between time intervals and between groups were compared using repeated measures ANOVA test and t-test, respectively. All data is expressed as the number of patients or mean \pm SD. A $P$ value $<0.05$ was considered significant.

\section{Results}

The success rate for the first tracheal intubation was significantly higher in Group A (96\%) than Group L (40\%) and the total intubation time required for successful intubation was significantly greater in Group L (90.0 seconds) than Group A (49.8 seconds). However, the duration of the successful intubation at first tracheal intubation attempt was similar in the two groups.

The first tracheal intubation attempt had succeeded in all patients in Group A with the exception of one case in whom the device could not be inserted into the oral cavity because the mouth opening was less than $2 \mathrm{~cm}$ after the cervical collar was applied. In contrast, there were 15 cases of failure during first intubation attempt in Group L and 4 cases of failure in the second attempt using cricoid pressure and stylet, which resulted in the removal of the cervical collar for intubation. The Cormack-Lehane grade of these four cases were all marked 2 without neck immobilization. The POGO score was significantly higher in Group A than Group L (Table 2).

Table 2. Intubation Profiles

\begin{tabular}{lcc}
\hline & $\begin{array}{c}\text { Group L } \\
(\mathrm{n}=25)\end{array}$ & $\begin{array}{c}\text { Group A } \\
(\mathrm{n}=25)\end{array}$ \\
\hline Successful intubation time (sec) & & \\
$\quad$ Total & $90.0 \pm 49.4$ & $49.8 \pm 33.6^{*}$ \\
$\quad$ At first attempt & $46.0 \pm 15.1$ & $44.4 \pm 20.2$ \\
Intubation attempts & $1.8 \pm 0.8$ & $1.1 \pm 0.4^{*}$ \\
Success rates & & \\
$\quad$ At first attempt & $10(40 \%)$ & $24(96 \%)^{*}$ \\
At second attempt & $21(84 \%)$ & $24(96 \%)$ \\
POGO (\%) & & \\
At first attempt & $6.4 \pm 10.9$ & $83.6 \pm 20.0^{*}$ \\
At second attempt & $15.0 \pm 17.0$ & $83.6 \pm 20.0^{*}$ \\
\hline
\end{tabular}

Values are number or mean \pm SD. Group L: conventional laryngoscope group, Group A: Airtraq group, POGO: percentage of glottic openings. *P $<0.05$ compared to Group L. 
Table 3. Hemodynamic Data

\begin{tabular}{lcc}
\hline & $\begin{array}{c}\text { Group L } \\
(\mathrm{n}=25)\end{array}$ & $\begin{array}{l}\text { Group A } \\
(\mathrm{n}=25)\end{array}$ \\
\hline $\begin{array}{l}\text { Mean blood pressure (mmHg) } \\
\quad \text { Baseline }\end{array}$ & $101.3 \pm 13.1$ & $98.1 \pm 14.0$ \\
$\quad \begin{array}{l}\text { Before intubation } \\
\text { After intubation }\end{array}$ & $77.0 \pm 9.9^{*}$ & $78.9 \pm 16.3^{*}$ \\
Heart rate (bpm) & $100.4 \pm 17.6^{\dagger}$ & $92.9 \pm 18.9^{\dagger}$ \\
$\quad$ Baseline & & \\
$\quad$ Before intubation & $77.2 \pm 11.6$ & $74.2 \pm 11.7$ \\
After intubation & $76.0 \pm 13.6$ & $69.8 \pm 10.2$ \\
\hline
\end{tabular}

Values are number or mean \pm SD. Group L: conventional laryngoscope group, Group A: Airtraq group. ${ }^{*} \mathrm{P}<0.05$ compared to baseline. ${ }^{\dagger} \mathrm{P}<0.05$ compared to before intubation. There were no differences between the two groups.

Mean blood pressure before intubation was significantly decreased as compared with the baseline value in both groups. Heart rate after intubation was significantly increased as compared with those of baseline and before intubation in both groups. But, there were no significant differences between the two groups (Table 3). Of the 50 patients studied, there were no serious complications related to anesthesia and airway management.

\section{Discussion}

This study demonstrated that Airtraq provides more effective and easier intubation conditions in patients with a Philadelphia cervical collar than the Macintosh laryngoscope. The manual in-line stabilization is a widely accepted neck immobilization technique [11]. However, the reports that this method increases the risk of subluxation $[2,12]$ and the requirements of a method-acknowledged assistant makes the value of this method doubtful. A Philadelphia cervical collar was used for neck immobilization in this study because patients with a suspected cervical spine injury are transported to the operating room with this device and removing this device can also cause considerable spinal movement.

During the airway management procedures, the degree of cervical spine motion varies according to the intubation techniques [13-15]. Oral intubation with neck immobilization is accepted as a feasible method in trauma patients suspected of having a cervical injury [16]. However, this neck immobilization has been shown to worsen the laryngoscopic views and decrease the inter-incisor distance [17]. These reports were confirmed by our results that all patients who had failed to intubate with neck immobilization had Cormack-Lehane grades 2 without neck immobilization.

The Airtraq has advantages in both mouth opening limitation and poor laryngeal view settings $[6,18]$. Exaggerated curvature of the Airtraq blade removes the requirement of neck extension to align the oral, pharyngeal and tracheal axes, and an internal arrangement of optical components makes intubation possible for patients with small mouths (Fig. 1). The better POGO score recorded in Group A demonstrated that better intubation conditions are offered by the Airtraq in patients with a Philadelphia cervical collar, which leads to a higher overall success rate compared to the conventional laryngoscopy.

In this study, the Airtraq has failed to show significant decrease in hemodynamic changes as reported in other studies $[6,19]$. Though the mean blood pressure increases to a maximum with laryngoscopy, the heart rate increases to a maximum with endotracheal intubation [20]. This may be one of the reasons that the changes in heart rate were similar in the two groups after intubation in this study. The usage of remifentanil throughout the procedures which has been proved to prevent the hemodynamic changes during airway management [20-22], may explain the lack of a significant decrease in hemodynamics in this study.

Conventional laryngoscopy is the most familiar device for anesthesiologists to perform intubation. However, the Airtraq device is very easy to learn and perform intubation in difficult airway settings [23]. This appears to be the reason for similar successful intubation time at first attempt in the two groups. The limitation of this study was that the anesthesiologist could not be blinded to the devices used despite efforts made to avoid the researchers' subjective decisions in the laryngeal views.

In conclusion, the Airtraq produced a superior laryngeal view over the Macintosh laryngoscope in patients with a Philadelphia cervical collar without any differences in hemodynamics or intubation time.

\section{References}

1. Bohlman HH. Acute fractures and dislocations of the cervical spine: an analysis of three hundred hospitalized patients and review of the literature. J Bone Joint Surg Am 1979; 61: 1119-42.

2. Manoach S, Paladino L. Manual in-line stabilization for acute airway management of suspected cervical spine injury: historical review and current questions. Ann Emerg Med 2007; 50: 236-45.

3. Malik MA, Subramaniam R, Churasia S, Maharaj CH, Harte BH, Laffey JG. Tracheal intubation in patients with cervical spine immobilization: a comparison of the Airwayscope, LMA CTrach, and the Macintosh laryngoscopes. Br J Anaesth 2009; 102: 654-61.

4. Komatsu R, Kamata K, Hoshi I, Sessler DI, Ozaki M. Airway scope and gum elastic bougie with Macintosh laryngoscope for tracheal intubation in patients with simulated restricted neck mobility. Br J Anaesth 2008; 101: 863-9.

5. Sakles JC, Rodgers R, Keim SM. Optical and video laryngoscopes for emergency airway management. Intern Emerg Med 2008; 3: 139-43.

6. Maharaj CH, Buckley E, Harte BH, Laffey JG. Endotracheal intubation in patients with cervical spine immobilization: a comparison of macintosh and airtraq laryngoscopes. Anesthesiology 
2007; 107: 53-9.

7. Heath KJ. The effect of laryngoscopy of different cervical spine immobilisation techniques. Anaesthesia 1994; 49: 843-5.

8. Gerling MC, Davis DP, Hamilton RS, Morris GF, Vilke GM, Garfin $\mathrm{SR}$, et al. Effects of cervical spine immobilization technique and laryngoscope blade selection on an unstable cervical spine in a cadaver model of intubation. Ann Emerg Med 2000; 36: 293-300.

9. Majernick TG, Bieniek R, Houston JB, Hughes HG. Cervical spine movement during orotracheal intubation. Ann Emerg Med 1986; 15: 417-20.

10. Levitan RM, Ochroch EA, Kush S, Shofer FS, Hollander JE. Assessment of airway visualization: validation of the percentage of glottic opening (POGO) scale. Acad Emerg Med 1998; 5: 919-23.

11. Walls RM. Airway management in the blunt trauma patient: how important is the cervical spine? Can J Surg 1992; 35: 27-30.

12. Lennarson PJ, Smith DW, Sawin PD, Todd MM, Sato Y, Traynelis VC. Cervical spinal motion during intubation: efficacy of stabilization maneuvers in the setting of complete segmental instability. J Neurosurg 2001; 94(2 Suppl): 265-70.

13. Turkstra TP, Craen RA, Pelz DM, Gelb AW. Cervical spine motion: a fluoroscopic comparison during intubation with lighted stylet, GlideScope, and Macintosh laryngoscope. Anesth Analg 2005; 101 : 910-5.

14. Turkstra TP, Pelz DM, Jones PM. Cervical spine motion: a fluoroscopic comparison of the AirTraq Laryngoscope versus the Macintosh laryngoscope. Anesthesiology 2009; 111: 97-101.

15. Hirabayashi Y, Fujita A, Seo N, Sugimoto H. A comparison of cervical spine movement during laryngoscopy using the Airtraq or
Macintosh laryngoscopes. Anaesthesia 2008; 63: 635-40.

16. Grande CM, Barton CR, Stene JK. Appropriate techniques for airway management of emergency patients with suspected spinal cord injury. Anesth Analg 1988; 67: 714-5.

17. Goutcher CM, Lochhead V. Reduction in mouth opening with semirigid cervical collars. Br J Anaesth 2005; 95: 344-8.

18. Norman A, Date A. Use of the Airtraq laryngoscope for anticipated difficult laryngoscopy. Anaesthesia 2007; 62: 533-4.

19. Ndoko SK, Amathieu R, Tual L, Polliand C, Kamoun W, El Housseini L, et al. Tracheal intubation of morbidly obese patients: a randomized trial comparing performance of Macintosh and Airtraq laryngoscopes. Br J Anaesth 2008; 100: 263-8.

20. Kovac AL. Controlling the hemodynamic response to laryngoscopy and endotracheal intubation. J Clin Anesth 1996; 8: 63-79.

21. Hwang JH, Kim YH, Lee JH, Jung YS, Go YK, Yoon MJ, et al. Comparison of effects of dentanyl, alfentanil and remifentanil on the cardiovasuclar response to endotracheal intubation during the induction of general anesthesia. Korean J Anesthesiol 2008; 54: 18 24.

22. Kim HT, Kim CK, Lee JH, Kwon YE, Lee JW, Kim DC. Effects of fentanyl and remifentanil on hemodynamic responses to endotracheal intubation during the induction of anesthesia with propofol. Korean J Anesthesiol 2006; 51: 552-7.

23. Maharaj CH, Costello J, Higgins BD, Harte BH, Laffey JG. Retention of tracheal intubation skills by novice personnel: a comparison of the Airtraq and Macintosh laryngoscopes. Anaesthesia 2007; 62: 272-8. 